\title{
NEW QUASI-STATIONARY THERMODYNAMIC APPROACH IN THE INTERNAL BALLISTICS AND THE INTERNAL COMBUSTION ENGINES
}

\author{
Marian Nikolov Mutafchiev \\ Todor Kableshkov University of Transport, Sofia, Bulgaria
}

(c) MESTE

JEL Category: Q40

\begin{abstract}
A new principal equation of the internal ballistics is presented herein, which is determining the temperature in the barreled firing weapons and the rocket engines with solid fuel during combustion of the charge. By this new equation it is demonstrated, that during "internal combustion" in the thermodynamic system is not enthalpy imported, but internal energy. On that basis equations, determining the temperature and pressure in the cylindrical space of a piston-type internal combustion engines during the working process, are developed. Equations, determining the average temperature in the chambers of the vane gas turbine engines are also developed. Equation, determining the temperature in the combustion chambers of rocket engines with liquid fuel is also developed. Equations for determining the pressure and temperature in the gas engine of automatic firing weapons as well as collectors of piston engines are also presented.
\end{abstract}

Keywords: Internal ballistics, internal combustion engines, rocket engines with liquid fuel

\section{INTRODUCTION}

In 1864 A. F. Rezal, a French scientist, had developed an equation, which thermodynamically describes the basic elements of the shot. At that time, the internal combustion engines still have not been invented. However, in 1910 the Russian scientist N. F. Drozdov published the first general methodology, which provides solutions of the internal ballistics' tasks. A little earlier in 1907 was published the first working theory of the internal combustion engines by the Russian Professor V.

Address of the author: Marian Nikolov Mutafchiev 棒" marian_mutafchiev@abv.bg
I. Grinevetski. By analyzing the theories of internal ballistics and the internal combustion engines of this period it is clear that both of them have nothing in common. This situation remained until the end of World War II and shortly thereafter. With the discovery of the electronic computing machines began the development of differential methods for engineering calculations. Namely one such method is a quasi-stationary thermodynamic process based on the first principle of thermodynamics for open thermodynamic system with fixed and mobile borders (Andiushenko, 1975) (Petrichenko \& et al., 1990). A new aspect of the method with regard on the theory of the internal combustion engines will be shown herein, caused by the author's experience to apply the 
terms of the internal ballistics and other aspects, relating to gas turbine engines and rocket engines with liquid fuel (Holshevnikov, K.V; Emin, O.N; Mitrohin, V.T;, 1986) (Vasiliev, A.P; Kuznecov, V.A; et al., 1993).

\section{ANALYSIS}

In general, in the presence of inflow and outflows, the equation of the first law of the thermodynamics according to the classical conception (Andiushenko, 1975) (Petrichenko \& et al., 1990):

$d Q+\sum_{j=1}^{k} i_{j} d m_{j}=d U+p d V$,

where: $d Q$ is the elementary quantity of heat, introduced or lead into the working substance; $\sum_{j=1}^{k} i_{j} d m_{j}$ - the energy flow imported (+) or removed $(-)$ with $j$ - elementary mass of the volume of the thermodynamic system $V ; i=u+p v$ - the specific enthalpy of influent or effluent gases; $p$ - the pressure in the system's volume; $d U$ - the elementary change in the system's internal energy.

In presence of a combustion process inside the thermodynamic system, the imported quantity of heat and produced gases as a result of chemical reaction do not overpass the system, i.e. they do not come from outside. In the case of the produced gases with elementary mass, the ejection energy - $p v$, which is due to an external source and is a component of enthalpy, is not reported. Therefore, the internal combustion leads to a modification only of the internal energy of the system - $u$. In this case, equation (1) is as follows:

$$
d Q+u_{\mathrm{g}} d m_{\mathrm{g}}+\sum_{j=1}^{k} i_{j} d m_{j}=d U+d L
$$

where: $u_{\mathrm{g}} d m_{\mathrm{g}}$ is the internal energy of the gases, produced as a result of the combustion.

The differential equation (2) is the first law of thermodynamics for open thermodynamic system with movable and fixed boundaries and internal source of gases and heat.

The internal ballistics is a science, which mainly represents the theory of thermodynamic and gas dynamic processes, taking place in the classic barreled and recoilless barreled firing weapons and rocket engines with solid fuel. For the conditions of the internal ballistics from equation (2) is obtained an equation, expressing the rate of

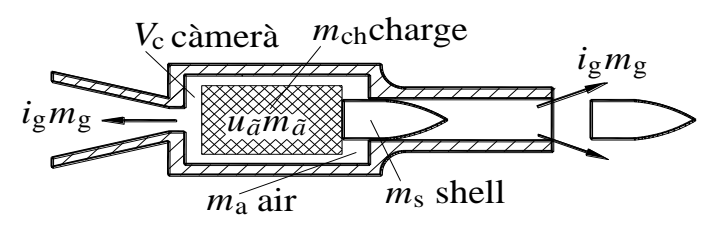

Fig. 1. Scheme and basic parameters of barreled weapon

change of the temperature in the barrel and the approximate scheme, shown in Fig. 1, under the following conditions: The working body has the properties of an ideal gas with the proviso that the co-volume (the volume of molecules) has been taken into account; the processes in which it is involved, are quasi-equilibrium. No restrictions are imposed on the development of the process. For continuously changing are accepted: the pressure $p$, the temperature $T$, the volume $V$.

Equation (2) can be written in the following way:

$d Q_{\mathrm{ch}}+u d m_{\mathrm{g}}-\sum_{1}^{n} i_{j} d m_{j}=d(M u)+p d V+d Q_{w}$,

where: $m_{\mathrm{g}}$ is the mass of the gases, produced as a result of the gunpowder's combustion; $M$ - the mass of the working substance in the barrel; $u$ the specific internal energy of the working substance in the barrel; $i_{j}$ and $m_{j}$ - the enthalpy and the mass of influent and effluent gases; $p$ the pressure of the working substance in the barrel; $d V$ - the change of the space's volume behind the projectile; $Q_{\mathrm{ch}}$ - the imported quantity of heat during the combustion of gunpowder; $Q_{w}$ - the quantity of heat, removed from the working substance as a result of heat exchange.

By taking into account the following relations, equation (3) is transformed: $d Q_{\mathrm{ch}}=\bar{Q}_{\mathrm{ch}} m_{\mathrm{ch}} d \psi$,

where: $\bar{Q}_{\mathrm{ch}}$ is the specific heat of combustion of the charge; $m_{\mathrm{ch}}$ - the mass of the charge; $\psi$ - the law of heat rejection and gas generation; $u d m_{\mathrm{g}}=c_{\mathrm{v}} T m_{\mathrm{ch}} d \psi$, where: $c_{\mathrm{v}}=\frac{R}{k-1}$ is the specific 
heat capacity at constant volume; $R$ - the gas constant of the working substance in the barrel; $k$ - the indicator of an adiabatic process. $i d m_{\mathrm{g}}=c_{p} T d m_{\mathrm{g}}$, where: $c_{p}$ is the specific heat capacity at constant pressure.

Consequently equation (3) obtains the following form:

$$
\begin{aligned}
\bar{Q}_{\mathrm{ch}} m_{\mathrm{ch}} d \psi+c_{\mathrm{v}} T m_{\mathrm{ch}} d \psi-c_{p} T d m_{\mathrm{g}} & = \\
= & M d u+u d M+p d V+d Q_{w}
\end{aligned}
$$

After dividing of the both sides of the equation on the magnitude $-M c_{\mathrm{V}} T$, and after grouping the following is obtained:

$$
\begin{aligned}
(k-1) & \frac{\bar{Q}_{\mathrm{ch}} m_{\mathrm{ch}} d \psi}{M R T}+\frac{m_{\mathrm{ch}} d \psi}{M}-k \frac{d m_{\mathrm{g}}}{M}= \\
= & \frac{d T}{T}+\frac{d M}{M}+(k-1) \frac{p d V}{M R T}+(k-1) \frac{d Q_{w}}{M R T}
\end{aligned} .
$$

Considering that during the combustion of an explosive charge are formed gases in addition to the heat release, then $d M=m_{\mathrm{ch}} d \psi+d m_{\mathrm{g}}$ from (5) is obtained

$$
\begin{gathered}
\frac{d T}{T}=(k-1) \frac{\bar{Q}_{\mathrm{ch}} m_{\mathrm{ch}}}{M R T} d \psi-(k-1) \frac{d m_{\mathrm{g}}}{M}-(k-1) \frac{d V}{V}- \\
-(k-1) \frac{d Q_{w}}{M R T}
\end{gathered} .
$$

The differential temperature after transformations is finally as follows:

$$
d T=(k-1) T\left(\frac{\bar{Q}_{\mathrm{ch}} m_{\mathrm{ch}}}{M R T} d \psi-\frac{d m_{\mathrm{g}}}{M}-\frac{d V}{V}-\frac{d Q_{w}}{M R T}\right) .
$$

The equation (6) gives the relation between the relative changes of the mass of the working substance, the cylinder's volume, the conditions of heat exchange and the relative amount of the introduced heat. It is a differential equation for determining the change in the temperature in the barrel and can be considered as a new basic equation of the internal ballistics.

The current value of the temperature in the barrel is calculated by the equation:

$$
T_{i}=T_{i-1}+(d T)_{i-1}
$$

The equation for the state is used to calculate the current value of the pressure.

Due to the great hardness of the differential law of the combustion of the charge $d \psi$ at the start and in the end of the combustion is better for the period of combustion of the charge to be used the integral form of the basic equation (6), because it comprises the integral law for combustion $\psi$, and the last one has another nature. After integrating (6), within the burning charge is obtained

$T_{i}=T_{0}+(k-1) T_{i-1}\left[\begin{array}{l}\frac{\bar{Q}_{\mathrm{ch}} m_{\mathrm{ch}} \psi_{i}}{M_{i} R T_{i-1}}-\frac{m_{\mathrm{eff} i}}{M_{i}}-\frac{\left(V_{i}-V_{0}\right)}{V_{i}}- \\ -\frac{Q_{w i}}{M_{i} R T_{i-1}}\end{array}\right]$

Where: $m_{\mathrm{eff} i}=\sum_{0}^{i} \Delta m_{\mathrm{eff} i}$ - the effluent gases and $Q_{w i}=\sum_{0}^{i} \Delta Q_{w i}$

For determining the current value of the volume is used the equation (Serebriakov, 1962) (Kuveko, A.E; Miropolski; F.P, 1987)

$$
V_{i}=V_{\mathrm{c}}+f x_{i}-(1-\psi) \frac{m_{\mathrm{ch}}}{\rho_{\mathrm{ch}}}-\alpha \psi m_{\mathrm{ch}},
$$

where: $V_{\mathrm{c}}$ is the volume of the chamber; $x_{i}$ - the current value of the path of the projectile; $(1-\psi) \frac{m_{\mathrm{ch}}}{\rho_{\mathrm{ch}}}$ - the volume, occupied by the unburned gunpowder; $\alpha \psi m_{\mathrm{ch}}$ - the volume of the molecules; $\rho_{\mathrm{ch}}$ - the charge density; $\psi$ - the coefficient of heat and gas release - analogous to the coefficient of active heat release in ICE; $\alpha$ - covolume (specific volume of the molecules).

If for the conclusion of the basic equation is not used equation (2) but equation (1), i.e. it is accepted that enthalpy is imported during combustion in the thermodynamic system, then equation (4) takes the following form

$$
\begin{aligned}
& \bar{Q}_{\mathrm{ch}} m_{\mathrm{ch}} d \psi+c_{p} T m_{\mathrm{ch}} d \psi-c_{p} T d m_{\mathrm{eff}}= \\
& =M c_{\mathrm{v}} d T+c_{\mathrm{v}} T d M+p d V+d Q_{w}
\end{aligned}
$$

Analogous transformations were made to afford:

$d T=(k-1) T\left(\begin{array}{l}\frac{\bar{Q}_{\mathrm{ch}} m_{\mathrm{ch}}}{M R T} d \psi+\frac{m_{\mathrm{ch}}}{M} d \psi-\frac{d m_{\mathrm{eff}}}{M}- \\ -\frac{d V}{V}-\frac{d Q_{w}}{M R T}\end{array}\right)$

Obviously, the difference between equations (6) and $(10)$ is the second member of the brackets 
(10), namely $\frac{m_{\mathrm{ch}}}{M} d \psi$. The difference that causes this member in the calculations for the speed of the bullet, pressure and temperature, made under equal other conditions, is a function of the pressure. The difference is $10-15 \%$ at a maximum pressure of about 1200 at. and were obtained values, which are greater than the actual and the calculated by equation (6). The dependence of the difference of the pressure is linear and at a maximum pressure of about 2500-3000 at. it exceeds $25 \%$. This proves that in the thermodynamic system during internal combustion is not imported enthalpy, but internal energy. For the piston internal combustion engines, for which in (Petrichenko \& et al., 1990) is applied equation (1), with a precondition for submission of enthalpy, in which the maximum pressure rarely exceeds 100at. this difference is in the range of $0.5-1.5 \%$ and it is difficult to detect in the general background of thermal, mechanical and other losses.

To describe the process in the channel between the barrel and the gas engine it is considered that the temperature in the connecting channel is different from the temperature in the barrel. In this case, the equation of the first law of thermodynamics for the conditions of the channel is the following:

$$
\begin{aligned}
& i d m_{\mathrm{in}}-i d m_{\mathrm{eff}}=d(M u)+d Q_{w} \\
& d T=(k-1) T\left(\frac{H_{u} g_{\mathrm{c}} d X}{M R T}-\frac{d V}{V}-\frac{d Q_{w}}{M R T}\right)+\frac{g_{\mathrm{c}} T d X}{M},
\end{aligned}
$$

where: $i d m_{\mathrm{in}}=c_{p} T_{\mathrm{b}} d m_{\mathrm{in}}$ is the enthalpy of the gases, which are incoming from the barrel; $T_{\mathrm{b}}$ - the gas temperature in the chamber; $i d m_{\text {eff }}=c_{p} T_{\text {chan }} d m_{\text {eff }}$ - the enthalpy of the effluent gases from the channel; $T_{\text {chan }}$ - the temperature of the gases in the channel.

After transformation of equation (11), as shown above, was obtained the equation describing the temperature variation in the accession channel

$$
d T_{\text {chan }}=\frac{T_{\text {chan }}}{M_{\text {chan }}}\left[\begin{array}{l}
\left(k \frac{T_{\mathrm{b}}}{T_{\text {chan }}}-1\right) d m_{\text {in }}-(k-1) d m_{\text {eff }}- \\
-(k-1) \frac{d Q_{w}}{R T_{\text {chan }}}
\end{array}\right]
$$

Using the differential form of the equation of the state $-\frac{d p}{p}=\frac{d M}{M}+\frac{d T}{T}$, the differential equation for the pressure in the channel was obtained,

$$
\begin{array}{r}
d p_{\text {chan }}=k \frac{p_{\text {chan }}}{M_{\text {chan }}}\left[\frac{T_{\mathrm{b}}}{T_{\text {chan }}} d m_{\text {in }}-d m_{\text {eff }}\right]- \\
-(k-1) \frac{d Q_{w}}{M_{\text {chan }} R T_{\text {chan }}} .
\end{array}
$$

For description of the process in the cylinder of the gas engine is considered that the temperature in the cylinder of the gas engine is different from the temperature in the connecting channel. In this case, the equation of the first law of thermodynamics under the conditions of cylinder gas engine will be the following:

$i d m_{\mathrm{in}}-i d m_{\mathrm{eff}}=d(M u)+p d V+d Q_{w}$,

where: $i d m_{\mathrm{in}}=c_{p} T_{\text {chan }} d m_{\text {in }}$ is the enthalpy of the incoming from the barrel gases; $T_{\text {chan }}$ - the gas temperature in the chamber; $i d m_{\mathrm{eff}}=c_{p} T_{\mathrm{ge}} d m_{\mathrm{eff}}$ the enthalpy of the effluent gases from the channel; $T_{\mathrm{ge}}$ - the temperature of the gases in the cylinder of the gas engine.

After processing of equation (14), as shown above, the equation describing the change in temperature in the cylinder of the gas engine was obtained

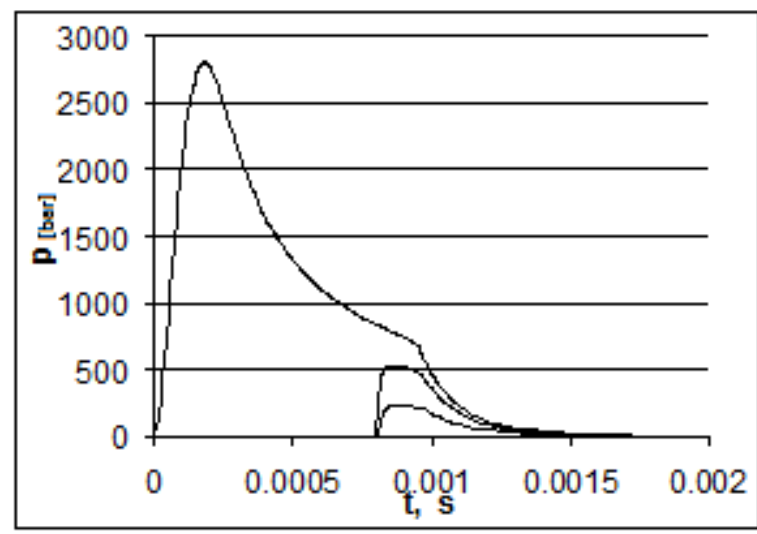

Fig. 2. Pressure variation in the barrel, in the accession channel and in the gas engine of 7,62x39 "Kalashnikov". 


$$
d T_{\mathrm{ge}}=T_{\mathrm{ge}}\left[\begin{array}{r}
\left(k \frac{T_{\mathrm{chan}}}{T_{\mathrm{ge}}}-1\right) \frac{d m_{\mathrm{in}}}{M_{\mathrm{ge}}}-(k-1) \frac{d m_{\mathrm{eff}}}{M_{\mathrm{ge}}}- \\
-(k-1) \frac{d V_{\mathrm{ge}}}{V_{\mathrm{ge}}}-(k-1) \frac{d Q_{w}}{M_{\mathrm{ge}} R T_{\mathrm{ge}}}
\end{array}\right]
$$

Using the differential form of the equation for the state $-\frac{d p}{p}+\frac{d V}{V}=\frac{d M}{M}+\frac{d T}{T}$, the differential equation for the pressure in the cylinder of the gas engine was obtained

$$
d p_{\mathrm{ge}}=p_{\mathrm{ge}}\left[\begin{array}{l}
k \frac{T_{\mathrm{K}} d m_{\mathrm{in}}}{T_{\mathrm{ge}} M_{\mathrm{ge}}}-k \frac{d m_{\mathrm{eff}}}{M_{\mathrm{ge}}}-k \frac{d V_{\mathrm{ge}}}{V_{\mathrm{ge}}}- \\
-(k-1) \frac{d Q_{w}}{M_{\mathrm{ge}} R T_{\mathrm{ge}}}
\end{array}\right]
$$

Fig.2. shows the pressure variation in the barrel, in the accession channel (middle curve) and the cylinder of the gas engine of "Kalashnikov" with 7,62X39 ammunition. The calculations were made by the expressions (6), (8), (13) and (16) respectively and with detailed mathematical modeling of the thermal and mechanical losses, the after-effect and the gas outflow. The process of leakage is proved with non-stationary gas dynamic model. The difference between the estimated factory value for the maximum pressure is $0,11 \%$ and for the speed in the barrel is $3 \%$ respectively.

The equations expressing the rate of change of the temperature and pressure in the cylinders of a piston internal combustion engine during the working process (with closed valves) are obtained from the equation (2) and the approximation scheme shown in Fig. 3. Equation (2) takes the following form

$$
d Q+u d m_{\mathrm{g}}=d(M u)+p d V+d Q_{w}
$$

Taking into account the following relations, equation (17) is transformed:

$$
d Q=H_{u} g_{c} d X
$$

where: $H_{u}$ is the lower specific heat of combustion of fuel; $g_{c}$ - the mass of the cycle portion of fuel; $X$ - the coefficient of heat release (of combustion);

$$
u d m_{\mathrm{g}}=c_{\mathrm{v}} T g_{\mathrm{c}} d X
$$

Furthermore, the coefficient of mole variation of piston engines is changing in a very narrow range of 1.15 to 1.01 , closer to unit, due to air ratio, then the mass variation of the gases during combustion can be ignored, i.e. $d M=0$. In this case, the differential of the temperature of the working process can be determined from (17) and obtains the following form,

$d T=(k-1) T\left(\frac{H_{u} g_{\mathrm{c}} d X}{M R T}-\frac{d V}{V}-\frac{d Q_{w}}{M R T}\right)+\frac{g_{\mathrm{c}} T d X}{M}$

The differential equation for pressure variation is obtained, using the differential form of the

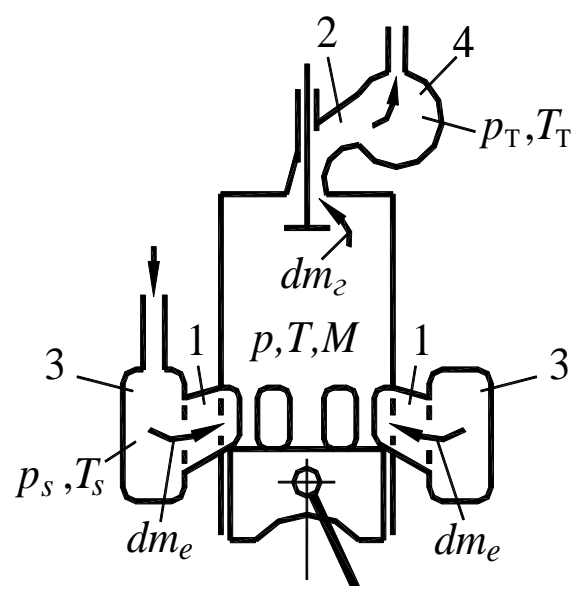

Fig. 3. Generalized scheme of an internal combustion engine

1 - ventilating windows; 2 - exhaust duct; 3 - filler receiver; 4 - exhaust receiver

equation of state.

$$
\begin{array}{r}
d p=p\left[(k-1) \frac{H_{u} g_{\mathrm{c}} d X}{M R T}+\frac{g_{\mathrm{c}} d X}{M}-k \frac{d V}{V}\right]- \\
-(k-1) \frac{p d Q_{w}}{M R T}
\end{array}
$$

To determine the temperature and pressure in the cylinder during the gas exchange processes is assumed that the temperature in the cylinder of the engine is different from the temperature in the filler collector, while the temperature in the outlet collector has a little difference to that in the cylinder. In this case, the equation of the first law of thermodynamics for the conditions of the engine cylinder will be the following, 
$i d m_{\text {in }}-i d m_{\mathrm{eff}}=d(M u)+p d V+d Q_{w}$,

where: $i d m_{\mathrm{in}}=c_{p} T_{\mathrm{fc}} d m_{\mathrm{in}}$ is the enthalpy of the inflowing gases from the filler collector; $T_{\mathrm{fc}}$ - the gas temperature in the filler collector; $i d m_{\mathrm{eff}}=c_{p} T d m_{\mathrm{eff}}$ - the enthalpy of the effluent gases from the cylinder of the engine; $T$ - the gas temperature in the cylinder of the engine.

After transformation of (19) are obtained the equations for determining the temperature

$d T=T\left[\begin{array}{r}\left(k \frac{T_{\mathrm{fc}}}{T}-1\right) \frac{d m_{\mathrm{in}}}{M}-(k-1) \frac{d m_{\mathrm{eff}}}{M}- \\ -(k-1) \frac{d V}{V}-(k-1) \frac{d Q_{w}}{M R T}\end{array}\right]$

and pressure

$d p=p\left[k \frac{T_{\mathrm{fc}} d m_{\mathrm{in}}}{T M}-k \frac{d m_{\mathrm{eff}}}{M}-k \frac{d V}{V}-(k-1) \frac{d Q_{w}}{M R T}\right]$

in the cylinder of the engine.

To determine the temperature and pressure in manifold is assumed that the temperature in the filler collector is different from the temperature in the engine cylinder. In this case, the equation of the first law of thermodynamics on the conditions of the collector will have the following form,

$i d m_{\mathrm{in}}-i d m_{\mathrm{eff}}=d(M u)+d Q_{w}$

where: $i d m_{\mathrm{in}}=c_{p} T_{\mathrm{c}} d m_{\mathrm{in}}$ is the enthalpy of the inflowing air from the compressor or atmosphere; $T_{\mathrm{c}}$ - the temperature of the inflowing air from the compressor or atmosphere; $i d m_{\mathrm{eff}}=c_{p} T_{\mathrm{fc}} d m_{\mathrm{eff}}$ the enthalpy of the effluent air from the filler collector; $T_{\mathrm{fc}}$ - air temperature in the filler collector.

After transformation of (23) are obtained the equations for determining the temperature

$d T_{\mathrm{fc}}=(k-1) \frac{T_{\mathrm{fc}}}{M_{\mathrm{fc}}}\left(d m_{\mathrm{in}}-d m_{\mathrm{eff}}-\frac{d Q_{w}}{R T_{\mathrm{fc}}}\right)$,

and pressure

$d p_{\mathrm{fc}}=k \frac{p_{\mathrm{fc}}}{M_{\mathrm{fc}}}\left(d m_{\mathrm{in}}-d m_{\mathrm{eff}}\right)-(k-1) \frac{d Q_{w}}{M_{\mathrm{fc}} R T_{\mathrm{fc}}}$,

in the filler collector of the engine.
To determine the temperature and pressure in the outlet collector equations are obtained which are identical with the equations (12) and (13), as the index "b" refers herein to the cylinder that acts as a barrel, and the index "chan" refers to the collector. It should be noted that the resulting equations for the collectors relate to one-cylinder engine or to the individual channel between the valve and the common part of the collector. To obtain equations relating to the general part of the collectors the elementary masses of influent and effluent gases of all cylinders must be added, dephased at the corresponding angle by the order of operation of the cylinders (Mutafchiev, 2002).

Equation (5) is used in order to obtain equation, which indicates the molar variation during the working process. The following equation is obtained:

$d T=T\left[\begin{array}{r}(k-1) \frac{H_{u} g_{\mathrm{c}} d X}{M R T}+\frac{g_{\mathrm{c}} d X}{M}-\frac{d M}{M}- \\ -(k-1) \frac{d V}{V}-(k-1) \frac{d Q_{w}}{M R T}\end{array}\right]$

As a result of the fuel combustion some gases are exhausted, others are formed. The mass of the gases obtained after combustion is slightly greater than the mass of the gases before combustion. The ratio of the mass of the combustion products to the mass of the gases prior combustion represents the molar coefficient of variation $\mu$. The following equation can be written for the mass variation of the gases during combustion

$d M=\mu g_{\mathrm{c}} d X$.

By replacing (27) in (26) is obtained

$$
\begin{gathered}
d T=(k-1) T\left(\frac{H_{u} g_{\mathrm{c}} d X}{M R T}-\frac{d V}{V}-\frac{d Q_{w}}{M R T}\right)+ \\
+(\mu-1) \frac{g_{\mathrm{c}} T d X}{M}
\end{gathered}
$$

The last member of the above equation becomes zero if the molar amendment is ignored, which means that the equivalent member in equation (18) can be ignored also under certain conditions.

Figure 4 shows the indicator diagram of D3900 four-cycle diesel engine of auto tractor, obtained by calculations, which are made with the equations (19) and (22). Comparisons are made with experimental data for the working process, 
obtained with piezo sensor and AVL digital recording equipment. The difference between the theoretical and experimental results for the range of the working process does not exceed $3 \%$.

In order to apply the method for the combustion chambers of gas turbine vane engines it is accepted that the temperature in the combustion chamber of the engine is different from the temperature of inflowing air, while the temperature of the effluent gases has a little difference with that of the combustion chamber. In that case, taking into account that the volume of the combustion chamber is a constant, the equation of the first law of thermodynamics for the conditions of the combustion chamber of the engine will be:

$d Q+u d m_{\mathrm{g}}+i d m_{\mathrm{in}}-i d m_{\mathrm{eff}}=d(M u)+d Q_{w}$,

where: $i d m_{\mathrm{in}}=c_{p} T_{\mathrm{in}} d m_{\mathrm{in}}$ is the enthalpy of the inflowing gases from the compressor; $T_{\text {in }}$ - the temperature of the inflowing gases from the compressor; $i d m_{\mathrm{eff}}=c_{p} T d m_{\mathrm{eff}}$ - enthalpy of the effluent gases through the turbine; $T$ - the gas temperature in the chamber of the engine; $d Q=H_{u} d m_{\mathrm{if}}$ - the imported quantity of heat; $d m_{\mathrm{if}}$ the elementary mass of the inflowing fuel; $u d m_{\mathrm{g}}=c_{\mathrm{v}} T d m_{\mathrm{if}}$ - the internal energy of the generated combustion gases; $d m_{\mathrm{g}}$ - the elementary gas mass, formed as a result of combustion, it is assumed that $d m_{\mathrm{g}}=d m_{\mathrm{if}}$.

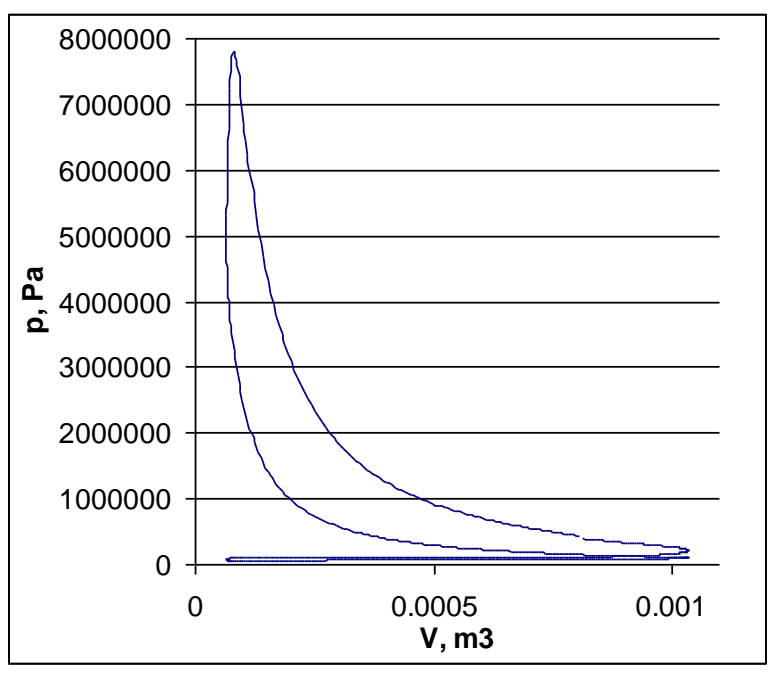

Fig. 4. Indicator diagram of D3900 four-cycle diesel engine of auto tractor.
After transformation of equation (28) for determining of the temperature it is obtained:

$d T=\frac{T}{M}\left[\begin{array}{c}(k-1)\left(\frac{H_{u}}{R T}+1\right) d m_{\mathrm{if}}+\left(k \frac{T_{\mathrm{in}}}{T}-1\right) d m_{\mathrm{in}}- \\ -(k-1) d m_{\mathrm{eff}}-(k-1) \frac{d Q_{w}}{R T}\end{array}\right]$

In the chamber of the rocket engine with liquid fuel, fuel and oxidant in a liquid phase enter, as there is an excess of oxidant. The excess oxidant passes into a gas phase not by combustion, but by evaporation whereat heat is absorbed. The absorbed heat by evaporation of the fuel and oxidant, which are involved in the combustion is even reported during the determination of the specific heat of combustion. For instance the specific heat of combustion of kerosene with liquid oxygen is four or five times less than the specific heat of combustion of kerosene with gaseous oxygen. In that case taking into account that the volume of the combustion chamber is a constant, the equation of the first law of thermodynamics will be the following,

$d Q+u d m_{\mathrm{g}}-i d m_{\mathrm{eff}}=d(M u)+d Q_{\mathrm{ox}}+d Q_{w}$,

where $d Q_{\mathrm{ox}}$ is the elementary quantity of heat, required for evaporation of the excess oxidant.

For equation (31) is obtained

$H_{u} d m_{\mathrm{if}}+c_{\mathrm{v}} T d m_{\mathrm{if}}-c_{p} T d m_{\mathrm{eff}}=M d u+u d M+$ $+d Q_{\mathrm{ox}}+d Q_{w}$

The equation determining the temperature is obtained after transformation of the above

$$
\begin{gathered}
d T=(k-1) \frac{T}{M}\left(\frac{H_{u} d m_{\mathrm{if}}}{R T}-d m_{\mathrm{eff}}-\frac{d Q_{\mathrm{ox}}}{R T}-\frac{d Q_{w}}{R T}\right)- \\
-\frac{T d m_{\mathrm{ox}}}{M}
\end{gathered}
$$

Fig. 5 shows the variation of pressure in the chamber of a rocket engine with liquid fuel. The temperature is determined by the equation (32) and the pressure with the state equation. The calculations are made for a conditional engine with 0.012 cubic meters volume of the chamber, $0.05 \mathrm{~m}$ diameter of the aperture, through which takes place the outflow, $40 \mathrm{~kg} / \mathrm{s}$ fuel consumption for the upper curve of the figure, with a coefficient of excess oxidant - 1.5. Kerosene is approved for fuel 


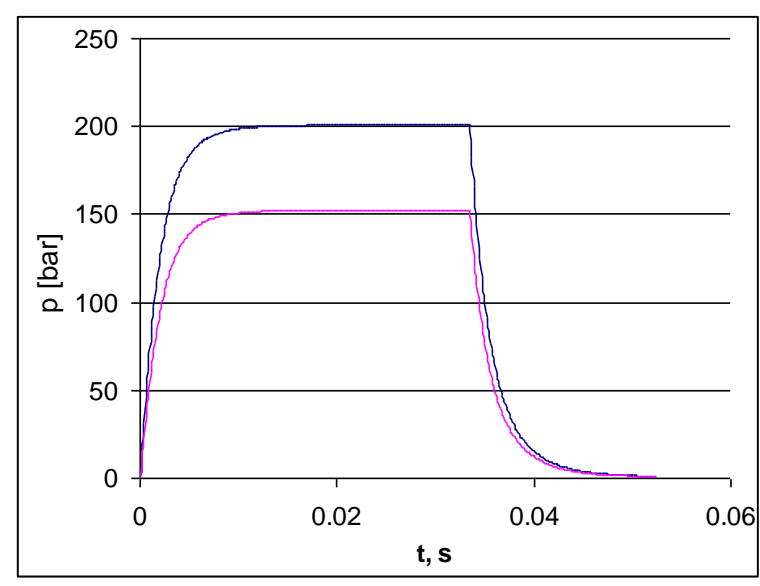

Fig. 5. Variation of pressure in the chamber of a rocket engine with liquid fuel.

and liquid oxygen for oxidant. In the figure clearly can be seen the starting process, established regime and engine braking.

\section{CONCLUSIONS}

The hypothesis that during addition of heat through combustion process that takes place in the workspace of the relevant technical object is not imported enthalpy, but internal energy, is proved. The developed equations for the internal ballistics and internal combustion engines have direct practical application in the design of new weapons and engines and in the optimization of existing constructions.

\section{WORKS CITED}

Andiushenko, A. (1975). Osnovi tehnicheskoj termodinamiki realnih procesov. Moskva: Vissh. shk.

Holshevnikov, K.V; Emin, O.N; Mitrohin, V.T;. (1986). Teoriia i raschet aviacionnih lopatychnih mashin. Moskva: Mashinostroenie.

Kuveko, A.E; Miropolski; F.P. (1987). Vnutrenniaia ballistika stvolnih sistem i raketnie dvigateli tverdogo topliva. Moskva: VVla N. E. Zhukovskogo.

Mutafchiev, M. (2002). Izsledvane na gazoobmennite procesi v dizelovite dvigateli s vytreshno gorene. Sofia: PhD thesis.

Petrichenko, R., \& et al. (1990). Elementi sistemi avtomatizirovannogo proektirovaniia DVS. Leningrad: Mashinostroenie.

Serebriakov, M. (1962). Vnutrenniaia ballistika stvolnih sistem i porohovih raket. Moskva: Oborongiz.

Vasiliev, A.P; Kuznecov, V.A; et al. (1993). Osnovi teorij i rascheta zhidkostnih raketnih dvigatelej (4 ed.). (V. M. Kudriavcev, Ed.) Moskva: Vish. shkola.

Received for publication:

11.04.2015

Revision received:

27.04 .2015

Accepted for publication:

10.05.2015

\section{How to cite this article?}

Style - APA Sixth Edition:

Mutafchiev, M. N. (2015, July 15). New quasi-stationary thermodynamic approach in the internal ballistics and the internal combustion engines. (Z. Čekerevac, Ed.) MEST Journal, 3(2), 90-98. doi:10.12709/mest.03.03.02.10

Style - Chicago Sixteenth Edition:

Mutafchiev, Marian Nikolov. 2015. "New quasi-stationary thermodynamic approach in the internal ballistics and the internal combustion engines." Edited by Zoran Čekerevac. MEST Journal (MESTE) 3 (2): 90-98. doi:10.12709/mest.03.03.02.10. 
Style - GOST Name Sort:

Mutafchiev Marian Nikolov New quasi-stationary thermodynamic approach in the internal ballistics and the internal combustion engines [Journal] // MEST Journal / ed. Čekerevac Zoran. - Belgrade : MESTE, July 15, 2015. - 2 : Vol. 3. - pp. 90-98.

Style - Harvard Anglia:

Mutafchiev, M. N., 2015. New quasi-stationary thermodynamic approach in the internal ballistics and the internal combustion engines. MEST Journal, 15 July, 3(2), pp. 90-98.

Style - ISO 690 Numerical Reference:

New quasi-stationary thermodynamic approach in the internal ballistics and the internal combustion engines. Mutafchiev, Marian Nikolov. [ed.] Zoran Čekerevac. 2, Belgrade : MESTE, July 15, 2015, MEST Journal, Vol. 3, pp. 90-98. 